\title{
DETERMINATION AND SEPARATION OF DIARYLHEPTANOIDS FROM ALDER GROWING IN LATVIA
}

\author{
Liga Roze $^{1,2}$, Oskars Bikovens ${ }^{1}$, Galina Telysheva ${ }^{1}$ \\ 1- Latvian State Institute of Wood Chemistry, 27 Dzerbenes Str., LV 1006 Riga, Latvia \\ Ph.: + (371) 67555916, fax: + (371) 67550635, e-mail: ligno@edi.lv \\ 2- University of Latvia, Faculty of Chemistry, Riga, Latvia
}

\begin{abstract}
The composition of diarylhepatnoids fraction isolated from bark of two alder species (grey alder and black alder) was studied. The efficiency of three extraction methods used for isolation of diarylhepatnoids from alder bark was compared. Two diarylhepatnoids: 1,7-bis-(3,4-dihydroxyphenyl)-heptan3-one-5-O- $\beta$-D-xylopyronoside (oregonin) and 1,7-bis-(3,4-dihydroxyphenyl)-3-hydroxyheptane-5-O- $\beta$-Dxylopyranoside were isolated from the bark of grey alder. The phenolic components of the extracts were analyzed by high-performance liquid chromatography (HPLC). Quantitative determination of oregonin was performed using an internal standard method. The results obtained show that alder barks are rich source of diarylhepatnoids.
\end{abstract}

Keywords: alnus species, bark extracts, diarylheptanoids, oregonin, 1,7-bis-(3,4-dihydroxyphenyl)-3hydroxyheptane-5-O- $\beta$-D-xylopyranoside.

\section{Introduction}

Large amounts of waste and byproducts are formed during wood mechanical and chemical processing. One of these wastes is bark usually used for energy production. However, bark of many tree species contains bioactive chemicals that can give added value to this resource [1]. The genus Alnus (Betulaceae) consists of about 35 species of deciduous trees and shrubs. At present, two alder species, grey alder (Alnus incana) and black alder (Alnus glutinosa) are of the great interest in for industrial application in Latvia [2].

Extractive compounds isolated from bark of Alnus spp. plants include numerous diarylhepatnoids along with triterpenoids. Diarylheptanoids belong to a class of natural products based on 1,7-diphenylheptane frame and appear in both linear and cyclic forms. It has been reported that diarylheptanoids reveal a strong antioxidant activity not only in food compositions but also in human/animal organisms providing high level of their protection [34]. One of the most known diarylheptanoids is 1,7-bis-(3,4-dihydroxyphenyl)-heptan-3-one-5O- $\beta$-D-xylopyronoside or oregonin, which displayed anti-inflammatory and antioxidant activities [5-6].

Traditionally, classical Soxhlet extraction is used for isolation of extractives from plant materials. New extraction methods have been introduced for reducing the amount of solvents, operation time and the cost of the procedure. Accelerated solvent extraction (ASE) and fluidized bed extraction (FBE) are among these new extraction techniques [7]. In the present study, a series of extracts were obtained from grey and black alder barks by three different extraction methods (Soxhlet, FBE and ASE) using organic solvents of different polarity (hexane, ethyl acetate and ethanol).

\section{Materials and methods}

The species examined in this work were grey alder (A.incana) and black alder (A.glutinosa). The barks were collected in Ogre, Latvia in July 2010. Bark was ground before extraction using a Wiley mill to pass a $420 \mu \mathrm{m}$ sieve.

Extraction and isolation

Barks $(5.00 \mathrm{~g})$ were extracted using three extraction methods: 
- Soxhlet extraction. Barks were sequentially extracted with $200 \mathrm{ml}$ of hexane, ethyl acetate and ethanol for 8 hours.

- FBE procedure was performed sequentially with $50 \mathrm{ml}$ of hexane, ethyl acetate and ethanol using IKA Solid-liquid extractor.

- In the ASE procedure the lipophilic extractives were first extracted with hexane (solvent temperature $90^{\circ} \mathrm{C}$, three 5-min static cycles), then more hydrophilic extractives were extracted with ethyl acetate in the same conditions and finally the hydrophilic extractives were isolated with ethanol (solvent temperature $100^{\circ} \mathrm{C}$, three 5 -min static cycles).

Diarylheptanoids were isolated from ethyl acetate extracts and purified by SP1 ${ }^{\mathrm{TM}}$ Purification System using Biotage column KP-C18-HS $(12$ x $150 \mathrm{~mm}, 35-70 \mu \mathrm{m})$ with solvent systems: solvent $\mathrm{A}=$ ethanol/ water/ acetic acid (200: 790: 10, v/v) and solvent $\mathrm{B}=$ ethanol. The gradient was from 0 to $25 \%$ solvent $\mathrm{B}$; injection volume $1 \mathrm{ml}$.

HPLC analysis of diarylheptanoids

HPLC analysis was performed with an HPLC Agilent Technologies 1100 Series coupled with a UV diode-array detector. The separation of the analytes was done with a column Zorbax Eclipse XDB - C18, 4,6 x $150 \mathrm{~mm}$. Elution was carried out with a flow rate of $1 \mathrm{ml} / \mathrm{min}$ using the following solvent systems: solvent $\mathrm{A}=$ water $/ \mathrm{methanol} /$ acetic acid $(890: 100: 10 \mathrm{v} / \mathrm{v})$ and solvent $\mathrm{B}=$ methanol. The elution conditions were: $0-20 \mathrm{~min} 25 \% \mathrm{~B}$; 20 - 25 min from $25 \%$ B to $100 \%$ B; $25-28$ min $100 \%$ B; 28 - 30 min from $100 \%$ B to $25 \%$ B. The operating conditions were: column temperature $30^{\circ} \mathrm{C}$; injection volume $20 \mu$. The oregonin calibration curve was made by diluting oregonin solutions with methanol to give concentration of the standard in the range $10-100 \mathrm{mg} / \mathrm{l}$. The curves were plotted from chromatograms as a peak area $v s$. concentration of the standard.

The reduction of ethyl acetate extracts by sodium tetrahydridoborate

One gram of A.incana ethyl acetate extract was dissolved in $20 \mathrm{ml}$ of methanol, and then $0.5 \mathrm{~g}$ of $\mathrm{NaBH}_{4}$ was added and the mixture was stirred for 1 hour at room temperature. The reaction solution was poured into $50 \mathrm{ml}$ of distilled water and diluted to $200 \mathrm{ml}$. Then the reaction solution was passed through a C18 column, washed with water and eluted with EtOH. The ethanol eluate was freeze-dried and analyzed with HPLC/MS using a reversed phase column and $25 \% \mathrm{MeOH}$ as solvent. The methanol eluate was purified by SP1 $1^{\mathrm{TM}}$ Purification System using Biotage column KP-C18-HS (12 x $\left.150 \mathrm{~mm}, 35-70 \mu \mathrm{m}\right)$ with solvent systems: solvent $\mathrm{A}=$ ethanol/ water/ acetic acid (200: 790: 10, v/v) and solvent $\mathrm{B}=$ ethanol. The gradient was from 0 to $15 \%$ solvent $\mathrm{B}$, injection volume $1 \mathrm{ml}$.

\section{Results and discussion}

The gravimetric amount of the extractives was determined for all alder bark extracts (Table 1). It is difficult to compare these results with earlier published data, since over the years a number of different solvents, including dichloromethane, chloroform, diethyl ether and acetone have been used. Each solvent dissolves slightly different amounts of material, and also different compounds, from the bark.

Comparison of efficiency of the extraction methods used

As shown in the Table 1, Soxhlet extraction, FBE and ASE have similar extraction efficiency for isolation of lipophilic extractives. It was found that the highest efficiency of diarylheptanoids extraction was obtained by Soxhlet procedure. At the same time, for such components of the ethanol extract as tannins or polyglycosides, ASE was more effective than other two extraction methods. These results are in good agreement with the data reported in the literature about extraction efficiency of different methods for analysis of terpenoids and sterols in tobacco [7]. 
Table 1.

Amounts of extractives isolated from A.incana and A. glutinosa barks, in w\% on o.d. bark

\begin{tabular}{|c|c|c|c|c|c|c|}
\hline \multirow{2}{*}{$\begin{array}{c}\text { Extraction } \\
\text { method }\end{array}$} & \multicolumn{2}{|c|}{ Hexane extract } & \multicolumn{2}{c|}{ Ethyl acetate extract } & \multicolumn{2}{c|}{ Ethanol extract } \\
\cline { 2 - 7 } & A.incana & A.glutinosa & A.incana & A.glutinosa & A.incana & A.glutinosa \\
\hline Soxhlet & 4.5 & 2.5 & 18.1 & 13.9 & 11.9 & 11.8 \\
\hline FBE & 4.3 & 2.4 & 14.8 & 12.8 & 12.8 & 12.0 \\
\hline ASE & 4.4 & 2.4 & 15.8 & 12.3 & 14.7 & 15.0 \\
\hline
\end{tabular}

Identification and quantification of diarylheptanoids

Compounds 1-2 were isolated from the ethyl acetate extracts. It was found using HPLCUV/MS analysis that the grey alder bark ethyl acetate extract contained a dominant compound with a molecular mass of $478 \mathrm{Da}$. This compound was isolated from grey alder bark ethyl acetate extract using Biotage SP1 ${ }^{\text {TM }}$ Purification System and identified from UV, FTIR, mass spectra and ${ }^{1} \mathrm{H},{ }^{13} \mathrm{C}-\mathrm{NMR}$ as 1,7-bis-(3,4-dihydroxyphenyl)-heptane-3-on-5-O- $\beta$-Dxylopyranoside or oregonin (1). The identification was based upon comparison of the results obtained with published data [8].

Reduction of oregonin with sodium tetrahydridoborate gave a mixture of 1,7-bis-(3,4dihydroxyphenyl)-3-hydroxyheptane-5-O- $\beta$-D-xylopyranoside (2) epimer alcohols.<smiles>O=C(CCc1ccc(O)c(O)c1)CC(CCc1ccc(O)c(O)c1)[OH+]C1OCC(O)C(O)C1O</smiles><smiles>Oc1ccc(CC[C@H](O)C[C@H](O)CCc2ccc(O)c(O)c2)cc1O</smiles>

Fig.1. Chemical structure of oregonin (1) and 1,7-bis-(3,4-dihydroxyphenyl)-3hydroxyheptane-5-O- $\beta$-D-xylopyranoside (2)

The content of oregonin in the ethyl acetate extract was determined from the calibration curve using the oregonin sample separated by Biotage SP1 ${ }^{\text {TM }}$ Purification System as a standard. The content of oregonin in ethyl acetate extract of grey alder bark was $80 \%$ or $20 \%$ on dry bark. The isolated oregonin could be utilized for example as antioxidant for health care.

Comparing the chromatogram retention times, UV, FTIR spectra, and molecular weight of reduced oregonin and an unknown compound isolated also from the ethyl acetate extract it was found that the grey alder bark contained small amounts of 1,7-bis-(3,4-dihydroxyphenyl)3-hydroxyheptane-5-O- $\beta$-D-xylopyranoside. Figure 2 showed (+)-ESI-MS spectrum and fragmentation of 1,7-bis-(3,4-dihydroxyphenyl)-3-hydroxyheptane-5-O- $\beta$-D-xylopyranoside. 


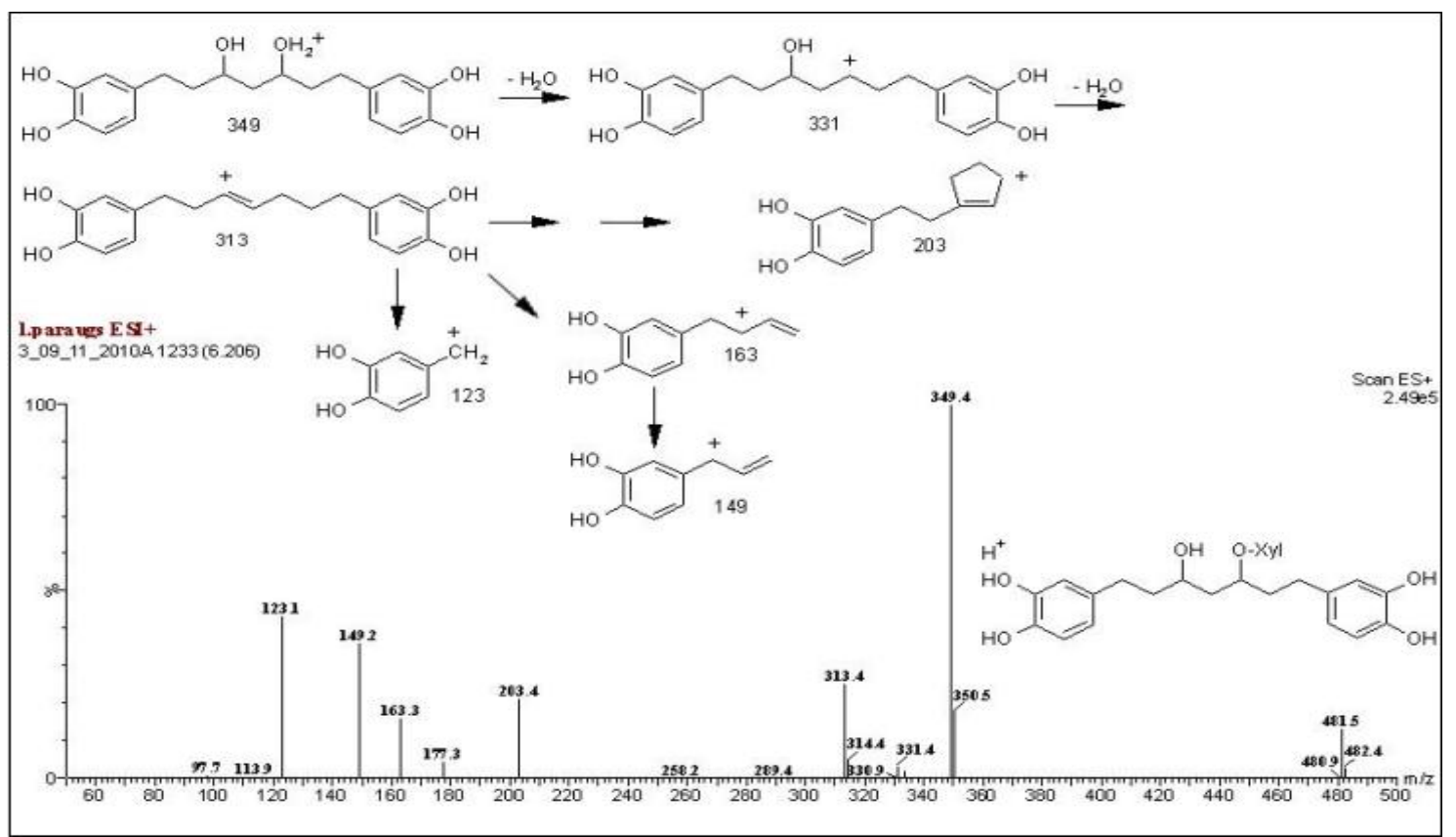

Fig.2. (+)ESI/MS mass spectrum and fragmentation of 1,7-bis-(3,4-dihydroxyphenyl)-3hydroxyheptane-5-O- $\beta$-D-xylopyranoside isolated from grey alder bark

\section{Conclusions}

The comparison of extraction results indicates that for components with high molecular mass ASE is more effective than other two extraction methods used, whereas the highest efficiency of diarylhepatnoids extraction was achieved Soxhlet extraction. Oregonin was isolated from grey alder ethyl acetate bark extract with $80 \%$ yield. It means that oregonin content in grey alder bark is of $20 \%$. The received results show that the grey alder bark is a prospective resource for production of valued diarylheptanoid - oregonin.

\section{Acknowledgement}

The financial support from the Latvian National Programme 3.2.5 (4-2) is gratefully acknowledged. Prof Dr Andrey Pranovich and Stefan Willför from Åbo Akademi, Wood and Paper Chemistry laboratory (Finland) are acknowledged for their help with ASE analysis.

\section{References}

1. Pietarinen S., Willför S., Ahotupa M., Hemming J. and Holmbom B. Knotwood and bark extracts: strong antioxidants from waste materials. J. Wood Sci., 52, 2006, pp. 436-444.

2. Pavlovics G., Antons A., Alksne A., Lavnikovica I., Cirule D., Dolacis J., Daugavietis M., Daugaviete M.Comparison of the anatomical structure elements and physical properties of the wood of different alder species growing in Latvia. Annals of Warsaw University of Life Sciences - SGGW, Forestry and Wood Technology, 69, 2009, pp. 173-177.

3. Kuroyanagi M., Shimomae M., Nagashima Y., Muto N., Okuda T. New diarylhepatnoids from Alnus japonica nad Their Antioxidative Activity. Chem. Pharm. Bull. 53, 2005, pp. 1519-1523.

4. Kim H.J., Kim K.H., Yeom S.H., Kim M.K., Shim J.G., Lim H. W., Lee M.W. New diarylheptanoid from the barks of Alnus japonica Steudel. Chin. Chem. Lett., 16, 2005, pp. 1337-1340.

5. Guz N.R., Lorenz P. and Métraux J.-P. Oregonin from the bark of European Alnus species. Biochem. Syst. Ecol. 30, 2002, pp. 471-474.

6. Kuo C.H., Lee C.W., Lai Y.C. and Lee S.S. Determination of oregonin in Alnus plants and biological samples by capillary electrophoresis. J. Pharm. Biomed. Anal. 47, 2008, pp. 195-200.

7. Shen J., Shao X. A comparison of accelerated solvent extraction, Soxhlet extraction, and ultrasonic-assisted extraction for analysis of terpenoids and sterols in tobacco. Anal Bioanal Chem, 383, 2005, pp. 1003-1008.

8. Suga T., Ohta S.,Hirata T., Aoki T. The absolute confuguration of diarylheptanoid xyloside, oregonin, isolated from the female flowers of Alnus serrulatoides. Chem. Lett., 1982, pp. 895-898. 